\title{
Pitfalls in the use of randomised controlled trials for fish oil studies with cardiac patients
}

\author{
Michael J. James ${ }^{1,2 *}$, Thomas R. Sullivan ${ }^{3}$, Robert G. Metcalf ${ }^{1}$ and Leslie G. Cleland ${ }^{1,2}$ \\ ${ }^{1}$ Rheumatology Unit, Royal Adelaide Hospital, Adelaide, SA, Australia \\ ${ }^{2}$ Discipline of Medicine, University of Adelaide, Adelaide, SA, Australia \\ ${ }^{3}$ Discipline of Public Health, University of Adelaide, Adelaide, SA, Australia \\ (Submitted 6 February 2014 - Final revision received 28 April 2014 - Accepted 9 May 2014 - First published online 16 June 2014)
}

\begin{abstract}
Randomised controlled trials (RCT) examining the effects of fish oil supplementation on cardiac outcomes have yielded varying results over time. Although RCT are placed at the top of the evidence hierarchy, this methodology arose in the framework of pharmaceutical development. RCT with pharmaceuticals differ in important ways from RCT involving fish oil interventions. In particular, in pharmaceutical RCT, the test agent is present only in the intervention group and not in the control group, whereas in fish oil RCT, $n$ - 3 fats are present in the diet and in the tissues of both groups. Also, early phase studies with pharmaceuticals determine pharmacokinetics and pharmacodynamics to design the dose of the RCT intervention so that it is in a predicted linear dose-response range. None of this happens in fish oil RCT, and there is evidence that both baseline $n-3$ intake and tissue levels may be sufficiently high in the dose-response range that it is not possible to demonstrate a clinical effect with a RCT. When these issues are considered, it is possible that the changing pattern of fish consumption and fish oil use over time, especially in cardiac patients, can explain the disparity where benefit was observed in the early fish oil trials but not in the more recent trials.
\end{abstract}

Key words: Randomised controlled trials: Fish oil: Cardiac patients

\section{Randomised controlled trials of $n-3$ fats in cardiac patients}

The first published randomised controlled trials (RCT) in this area began recruitment in 1983 and reported a beneficial effect of fish or fish oil consumption on all-cause mortality and IHD mortality ${ }^{(1)}$. Similarly, the next published RCT, which began recruitment in 1993, reported a beneficial effect of fish oil consumption on all-cause mortality, coronary death and sudden death ${ }^{(2)}$. These findings are in agreement with the results of prospective cohort studies that showed that increased fish consumption is associated with decreased CHD mortality ${ }^{(3,4)}$. However, RCT that recruited participants having $\mathrm{CHD}$ risk factors or existing $\mathrm{CHD}$ during the years 2002-2007 have reported no effect of fish oil supplementation $^{(5-8)}$. This review examines the temporal changes during these years that could have affected the suitability of RCT to be the most appropriate methodology for examining the effects of fish oil supplementation on cardiac outcomes. It also contrasts the nature of RCT with fish oil in cardiac patients with that of RCT in drug development, which is the origin of modern RCT methodology.
Randomised controlled trials have been placed at the top of the evidence hierarchy

The first publication of a blinded RCT in medicine is the Medical Research Council study on streptomycin in tuberculosis patients in 1947-1948. By 1970, the Food and Drug Administration required that evidence for drug efficacy be based on controlled clinical trials with by-group intentionto-treat analyses ${ }^{(9)}$. The acceleration of drug use in therapy with approximately 1200 drugs being approved by the Food and Drug Administration in the period 1950-2008 $8^{(10)}$ has undoubtedly reinforced the primacy of RCT for providing the proof of efficacy of an experimental treatment. This position has not been shaken by the generally accepted arguments that clinical drug trials have poor external validity $^{(11-13)}$, that the use of composite endpoints, which is very common, can provide statistical significance that is driven by the most prevalent but often least important component $^{(12,14)}$, and that in industry-funded trials the results and conclusions overwhelmingly favour the sponsor's product $^{(15)}$.

Abbreviations: ALA, $\alpha$-linolenic acid; CABG, coronary artery bypass grafting; RCT, randomised controlled trial.

*Corresponding author: M. J. James, email michael.james@health.sa.gov.au 


\section{Differences between trials with pharmaceuticals and} those with fish oil

RCT that examine the effects of $n-3$ fats from fish and/or fish oil on cardiovascular outcomes will share many of the limitations mentioned above. However, pharmaceutical RCT have at least one characteristic not shared by $n-3$ RCT. In drug trials, the test agent is administered to those in the experimental group, but not to those in the control group. In fish oil trials, the test agents, which are EPA and DHA, are present in both experimental and control groups.

In a RCT with a new drug, one group will receive the drug, usually at a dose determined from prior pharmacokinetic and pharmacodynamic studies. The control group will not receive the study drug and the blood concentrations of the study drug in the control group will be zero. In addition, it is standard practice to prohibit concomitant use of drugs with the same or similar action to the test drug. Thus, RCT with pharmaceuticals are designed to maximise the differences between the treatment arms and thereby optimise the chance of detecting an effect if it exists. This is in contrast to all RCT that have examined the effects of dietary fish and/or fish oil consumption on cardiac outcomes because the non-study intake of $n-3$ fats cannot be prevented.

\section{Non-study intake of $n-3$ fats from fish and fish oil in randomised controlled trials}

In any RCT that examines the effects of fish oil supplementation on cardiac outcomes, it would be advantageous to include participants with (1) a history of low $n$ - 3 intake at baseline and (2) zero-to-low non-study $n-3$ intake during the study.

A sample of seven of the larger RCT that examined the effects of fish or fish oil on cardiac outcomes were selected to span the period from the first large study that commenced in 1983 to a study that finished in $2012^{(1,2,5-8,16)}$. The average sample sizes of the seven RCT selected for this discussion were 3587 and 3581 for the fish oil and control groups, respectively. A recent meta-analysis $^{(17)}$ included studies in which six of the seven RCT cited herein were reviewed as well as studies with, for example, group sizes ranging between 18 and $60^{(18-20)}$. Therefore, our sample is not an exhaustive list such as might be used to examine clinical outcomes in a meta-analysis. It is used to demonstrate only the points on trial design that are the topic of this discussion. Of these seven RCT, only three paid attention to baseline exclusions relevant to $n-3$ intake. These were exclusion of those already taking fish oil supplements and unwilling to discontinue their use ${ }^{(5,6)}$ and exclusion of those intending to eat the intervention diet ${ }^{(1)}$. The other four RCT had no exclusions relevant to baseline or continuing non-study $n$ - 3 intake. It is not possible to prevent $n-3$ intake in the control group during the study. Participants may be instructed not to consume non-study $n$-3-containing oils, but the intake of EPA+DHA from fish is poorly controlled. None of the reports of the seven RCT indicated that the control group was instructed not to eat fish, to limit fish intake or even not to use $n-3$ supplements. In one study, $76 \%$ of the participants had consumed at least one fish meal per week, with 33\% consuming at least two fish meals per week $^{(8)}$ (Table 1). In only one study, it was stated that the use of non-study $n-3$ supplements was

Table 1. Advice or comments relevant to non-study $n-3$ intake in randomised controlled trials with fish or fish oil

\begin{tabular}{|c|c|c|c|}
\hline & $\begin{array}{l}\text { Recruitment period } \\
\text { and criteria }\end{array}$ & Follow-up & Comments relevant to $n-3$ intake \\
\hline DART- $1^{(1)}$ & $\begin{array}{l}\text { 1983-1987 } \\
\text { Mean } 41 \mathrm{~d} \text { after MI }\end{array}$ & 2 years & $\begin{array}{l}\text { 3-fold increase in EPA intake in the fish advice } v \text {. the control group } \\
\text { and comment 'there was little spontaneous tendency to } \\
\text { eat fatty fish in the group not given fish advice' }\end{array}$ \\
\hline GISSI-P(2) & $\begin{array}{l}\text { 1993-1995 } \\
\text { Within } 3 \text { months of MI }\end{array}$ & 3.5 years & $\begin{array}{l}\text { Participants were given leaflet advice on Mediterranean diet and all } \\
\text { groups increased their intake of fruit, vegetables, olive oil and } \\
\text { fish after their Ml and this remained steady during the trial }\end{array}$ \\
\hline DART- $2^{(16)}$ & $\begin{array}{l}1990-1992 \\
1993-1996 \\
\text { Angina }\end{array}$ & $3-9$ years & $\begin{array}{l}\text { In } 1999 \text { (at the end of the } 3-9 \text {-year follow-up), the fish intake was } \\
47.7 \mathrm{~g} / \mathrm{d} \text { in the fish advice group and } 39.4 \mathrm{~g} / \mathrm{d} \text { in the control group } \\
- \text { this difference was statistically significant }\end{array}$ \\
\hline Alpha Omega Study ${ }^{(6)}$ & $\begin{array}{l}2002-2006 \\
\text { MI up to } 10 \text { years before } \\
\text { randomisation } \\
\text { (median } 3 \cdot 7 \text { years) }\end{array}$ & Median 40 months & $\begin{array}{l}\text { No mention of advice on fish or fish oil consumption during the study. } \\
\text { At baseline, the median intake of EPA+DHA was } 130 \\
\text { (interquartile range } 60-210 \text { ) } \mathrm{mg} / \mathrm{d} \text {, and this presumably } \\
\text { continued. Use of non-study fish oil supplements during the trial } \\
\text { was reported by } 5 \% \text { of the participants }\end{array}$ \\
\hline $\mathrm{OMEGA}^{(7)}$ & $\begin{array}{l}2003-2007 \\
3-14 \mathrm{~d} \text { after acute } \mathrm{MI}\end{array}$ & 1 year & $\begin{array}{l}\text { No mention that fish oil intake was proscribed. The separate } \\
\text { paper on study design stated that compliance would be measured } \\
\text { by blood EPA+DHA levels }{ }^{(53)} \text {, but this did not appear in the } \\
\text { main paper. Fish consumption was common at baseline and } \\
\text { increased in both groups during the study }\end{array}$ \\
\hline ORIGIN ${ }^{(5)}$ & $\begin{array}{l}2003-2005 \\
\text { At-risk subjects (e.g. diabetes } \\
\quad \text { or previous MI or angina) }\end{array}$ & Median 6.2 years & $\begin{array}{l}\text { Statement in publication - 'We made no } \\
\text { study-specific dietary recommendations pertaining to } \\
\text { consumption of fish or other marine products. However, the use of } \\
\text { non-study supplements containing } n-3 \text { fatty } \\
\text { acids was discouraged' }\end{array}$ \\
\hline $\begin{array}{l}\text { Risk and } \\
\text { Prevention } \\
\text { Study }\end{array}$ & $\begin{array}{l}2004-2007 \\
\text { At-risk subjects } \\
\text { but no prior MI }\end{array}$ & Median 5 years & $\begin{array}{l}76 \% \text { of the study population consumed fish at least once a week } \\
\text { with } 33 \% \text { consuming fish two or more times a week. There were } \\
\text { no reported recommendations on the use of fish oil supplements }\end{array}$ \\
\hline
\end{tabular}

DART, Diet and Reinfarction Trial; GISSI-P, GISSI-Prevenzione trial; MI, myocardial infarction; ORIGIN, Outcome Reduction with Initial Glargine Intervention. 
'discouraged', although it was also stated that 'We made no study-specific dietary recommendations pertaining to consumption of fish or other marine products ${ }^{\text {(5) }}$ (Table 1 ). Non-study $n-3$ intake could decrease the difference in $n-3$ status between the intervention and control groups. One of the studies, known as Diet and Reinfarction Trial-2 (DART-2) in which the participants were recommended to eat two meals of oily fish per week, reported that fish intake at the end of the follow-up period was $47.7 \mathrm{~g} / \mathrm{d}$ in the fish advice group and $39.4 \mathrm{~g} / \mathrm{d}$ in the no-fish advice group ${ }^{(21)}$. These intakes were statistically significantly different, but such a small difference is unlikely to be functionally significant.

The RCT under discussion recruited over a period spanning from 1983 to 2007 (Table 1). The start of recruitment falls into two periods, namely $1983-1993^{(1,2,16)}$ and $2002-2004^{(5-8)}$. The use of non-study fish oil supplements may not have been a substantive problem in the early trials, but it is more likely that non-study fish oil or increased fish intake may have occurred in the later trials as community and food industry awareness of $n-3$ fats increased and the availability of fish oil supplements increased. The advice given by the American Heart Association in 1961 made no distinction among different types of polyunsaturates ${ }^{(22)}$. In the Nurses' Health Study and the Health Professionals Follow-up Study, which surveyed participants' supplement intake from 1980 to 1986, respectively, no questions on fish oil intake were asked until 1988. In 1990, 1.6 and $3.3 \%$ of the female and male participants, respectively, were taking a fish oil supplement, and by 2006 , these values were 18.1 and $22 \cdot 2 \%{ }^{(23)}$

By 2000, the American Heart Association recommended that $\geq 2$ fish meals per week be consumed, and by 2002, the American Heart Association recommendation included fish and/or fish oil supplementation for those with $\mathrm{CHD}^{(24,25)}$. It is difficult to determine when fish oil came into community use to an extent that cardiac patients similar to those participating in these trials were likely to use it. However, it is presumed that the production of refined fish oil for human consumption followed demand. The change in uses of fish oil in the last 50 years with mainly hardened oils being used for margarines and negligible production of refined oils for human $n$ - 3 consumption in 1960 suggests that before 1990 the use of fish oil supplements was negligible and certainly not at levels observed today $^{(26)}$ (Table 2).

Importation of fish oil into the USA accelerated after $2000^{(27)}$ along with the changing advice of the American Heart Association in $2000^{(24)}$. Thus, during the period of recruitment and follow-up in the recent trials, ranging from 2002 to $2012^{(5-7)}$, fish oil supplements had become available, which makes it more likely that they were being used by cardiac patients such as those participating in the trials (Fig. 1).

Thus, during the period of commencement of these RCT, starting in 1983 and extending to 2007, it may have become increasingly difficult to recruit subjects with low baseline $n-3$ intake from marine sources and to maintain low $n-3$ intake from marine sources in the control group for the trial duration unless specific instructions were given and reinforced during the trial.
Table 2. Change in the uses of fish oil ${ }^{\star}$

\begin{tabular}{lccc}
\hline & \multicolumn{3}{c}{ Percentage of total use } \\
\cline { 2 - 4 } & 1960 & 1990 & 2010 \\
\hline Hydrogenated for edible use & 80 & 59 & 2 \\
Industrial (coatings, lubricant, etc.) & 20 & 20 & 3 \\
Aquaculture feed & - & 16 & 71 \\
Refined for human $n-3$ consumption & - & 5 & 24 \\
\hline
\end{tabular}

${ }^{*}$ Adapted from Shepherd \& Jackson ${ }^{(26)}$.

Non-study intake of $n-3$ fats from non-marine sources in randomised controlled trials

The $n-3$ fatty acids, EPA and DHA, are present not only in fish and fish oil, but also in red meat, eggs and dairy products. Although EPA and DHA are present in much higher quantities in fish than in red meat and poultry, almost half of the average long-chain $n$-3 PUFA intake for adult Australians originates from food other than fish, and this reflects the 6-fold higher intake of red meat and poultry compared with that of fish and seafood ${ }^{(28)}$. In addition, the long-chain $n$-3 PUFA can be synthesised from dietary $\alpha$-linolenic acid (ALA), which is present in vegetable oils such as rapeseed and soyabean and in smaller amounts in leafy green vegetables, although conversion is limited. Dietary ALA is capable of modestly increasing tissue EPA levels in short-term studies, although most studies have not reported increases in DHA levels as a proportion of total fatty acids ${ }^{(29)}$. However, radiotracer studies have shown that dietary ALA can be a precursor of DHA in men and to a greater extent in women ${ }^{(30)}$, and this is supported by the presence of plasma DHA in vegans at levels only slightly lower than those present in omnivores ${ }^{(31,32)}$. Thus, even if trial subjects do not take fish oil supplements or eat fish, they will have EPA and DHA in their tissues, which originate from dietary ALA, EPA and DHA in omnivores and dietary ALA in vegans.

\section{Tissue EPA and DHA}

Erythrocyte EPA+DHA levels are closely correlated with human myocardial EPA+DHA levels ${ }^{(33)}$. Whole-blood or erythrocyte EPA+DHA levels are also correlated with the

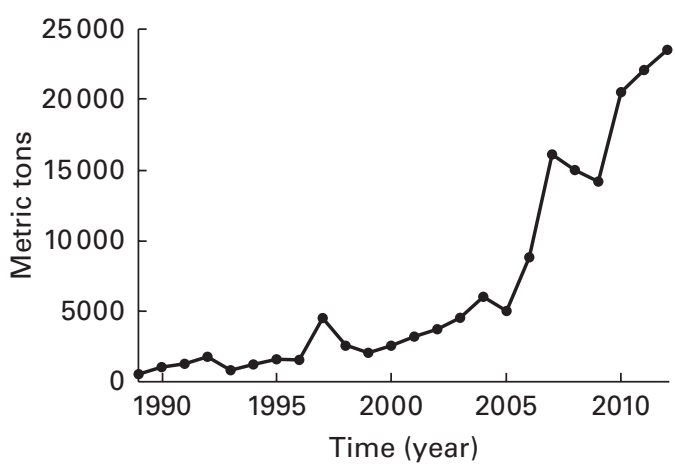

Fig. 1. Quantity of $n-3$ oils imported into the USA (adapted from Bimbo ${ }^{(27)}$ ). 
risk of sudden cardiac death and primary cardiac arrest ${ }^{(34,35)}$. A correlation between CHD mortality and erythrocyte EPA+DHA levels, the 'omega-3 index', has been observed in cohort, case-control and intervention studies ${ }^{(36)}$. Thus, the biochemical and physiological effects of dietary EPA and DHA are most probably due to their levels in the target tissue, which, for prevention of arrhythmias, is the myocardium.

There is an implicit expectation that the randomised allocation will create two distinct groups with regard to both $n-3$ intake and subsequent tissue levels of EPA+DHA. This is probably not the case in part due to non-study $n$ - 3 intake as discussed above and also due to non-linear doseresponses and to variability from unexplained non-dietary sources. Data from the Cardiovascular Health Study cohort showed a non-linear relationship between intake and plasma phospholipid EPA+DHA levels, with the steepest dose-response being observed at intakes up to approximately $400 \mathrm{mg} / \mathrm{d}$ and smaller increases in plasma EPA+DHA levels occurring thereafter ${ }^{(37)}$. Modelling of data from the Framingham Offspring cohort indicated that the dietary intake of EPA+DHA and fish oil supplementation accounted for only 25 and $15 \%$, respectively, of the variation in erythrocyte EPA+DHA levels ${ }^{(38)}$. This is supported by intervention studies that have shown up to 10 -fold variation in plasma phospholipid or erythrocyte EPA levels in healthy volunteers given purified EPA and substantial variation in erythrocyte EPA+DHA levels only partially explained by the dose of fish oil ${ }^{(39-41)}$.

Thus, a RCT with a fish oil intervention may not have distinct groups in relation to tissue EPA+DHA content, and this could be due to a combination of non-study $n-3$ intake and variability in tissue levels that is related to factors other than $n-3$ intake, both of which have been highlighted by others ${ }^{(42-44)}$.

This outcome is illustrated by examining erythrocyte EPA+DHA levels in subjects who participated in a RCT that examined the effects of fish oil on post-operative atrial fibrillation after cardiac surgery ${ }^{(45)}$. Effort was made to recruit subjects with a low erythrocyte EPA+DHA content at baseline. Potential subjects were excluded if they had consumed $\geq 1$ fish meal per week or they had taken fish oil supplements. Most of those excluded from the RCT agreed to be followed in an observation group. The RCT intervention was oral fish oil containing $4.5 \mathrm{~g} / \mathrm{d}$ of EPA+DHA for 3 weeks before the scheduled date of surgery. The control group consumed Sunola oil, a monounsaturated sunflower oil containing no measurable EPA or $\mathrm{DHA}^{(45)}$. The fish oil group had significantly increased mean erythrocyte EPA+DHA levels at the time of surgery than at the baseline and compared with the control group at the time of surgery (Table 3).

However, the scatter plots demonstrated the substantial overlap in EPA+DHA values between the control and fish oil groups after the intervention, i.e. at the time of surgery (Fig. 2). In fact, the upper $50 \%$ of the control subjects and the lower $50 \%$ of the fish oil subjects could be in the alternate group at the time of surgery. Also, subjects in the observation group, who were those who did not meet the inclusion criterion of consuming $\leq 1$ fish meal per week
Table 3. Erythrocyte EPA+DHA levels in a randomised controlled trial of fish oil intervention for post-operative atrial fibrillation after cardiac surgery ${ }^{(45)}$

(Mean values, standard deviations and number of participants)

\begin{tabular}{|c|c|c|c|c|c|c|}
\hline & \multicolumn{6}{|c|}{ Percentage of total fatty acids } \\
\hline & \multicolumn{2}{|c|}{$\begin{array}{c}\text { Control } \\
\text { group }^{*}(n 71)\end{array}$} & \multicolumn{2}{|c|}{$\begin{array}{c}\text { Fish oil } \\
\text { group } \\
(n 66)\end{array}$} & \multicolumn{2}{|c|}{$\begin{array}{l}\text { Observation } \\
\text { group } \neq \\
(n 44)\end{array}$} \\
\hline & Mean & SD & Mean & SD & Mean & SD \\
\hline Baseline & $5 \cdot 9^{\mathrm{a}}$ & 0.92 & $5 \cdot 9^{\mathrm{a}}$ & $1 \cdot 1$ & & \\
\hline $\begin{array}{l}\text { At surgery } \\
\quad(3 \text { weeks later) }\end{array}$ & $5 \cdot 8^{\mathrm{a}}$ & 0.92 & $8 \cdot 8^{\mathrm{b}}$ & $1 \cdot 7$ & $9 \cdot 0^{\mathrm{b}}$ & $1 \cdot 8$ \\
\hline
\end{tabular}

${ }^{\mathrm{a}, \mathrm{b}, \mathrm{c}}$ Mean values with unlike superscript letters were significantly different $(P<0.05$; linear mixed-effects model with post hoc Tukey's test).

${ }^{*}$ Consumed monounsaturated oil for 3 weeks before surgery.

† Consumed fish oil concentrate supplying $4.5 \mathrm{~g} / \mathrm{d}$ of EPA+DHA for 3 weeks before surgery.

$\ddagger$ Excluded from the trial due to the consumption of one or more than one fish meal per week or fish oil supplementation - agreed to be followed.

or not ingesting fish oil, had mean and individual values indistinguishable from the fish oil group after the intervention (Table 3 and Fig. 2).

Thus, unless modern $n-3$ studies with cardiac patients exclude potential subjects on the basis of their background fish or fish oil intake, it is unlikely that any dietary $n-3$ intervention will create a distinct group with regard to tissue EPA+DHA levels. This will be exacerbated if there is no rigorous exclusion of those consuming marine $n-3$ fats from the control group during the study.

\section{Problems arising from the 'test agent', EPA+DHA, being} present in both the control and intervention groups

The overlap in EPA+DHA levels between the treatment and control arms has important implications for the final statistical comparisons. For binary outcomes, i.e. those with only two possible results such as a fatal heart attack occurring or not occurring, it is beneficial to maximise the mean difference in EPA+DHA levels between the treatment groups. For an adverse binary outcome, one can suppose that higher levels of EPA+DHA following intervention are associated with lower probabilities of experiencing the adverse event. For a fixed event rate in the control arm, a decreased distance between the mean EPA+DHA levels of the control and intervention groups will be associated with a smaller difference in event rates due to treatment and a subsequent decrease in the power to detect differences between the groups for a given sample size. In the case of continuous outcomes, both the mean difference between the groups and the variability within the groups with regard to EPA+DHA levels are important. When assuming a linear association between the levels of EPA+DHA following intervention and the mean of some continuous outcome, an increase in the within-group variability of EPA+DHA levels will result in an increase in the within-group variability of the continuous outcome, which in turn will reduce the power to detect a given effect size. Consequently, for continuous outcomes, one should try to maximise the 


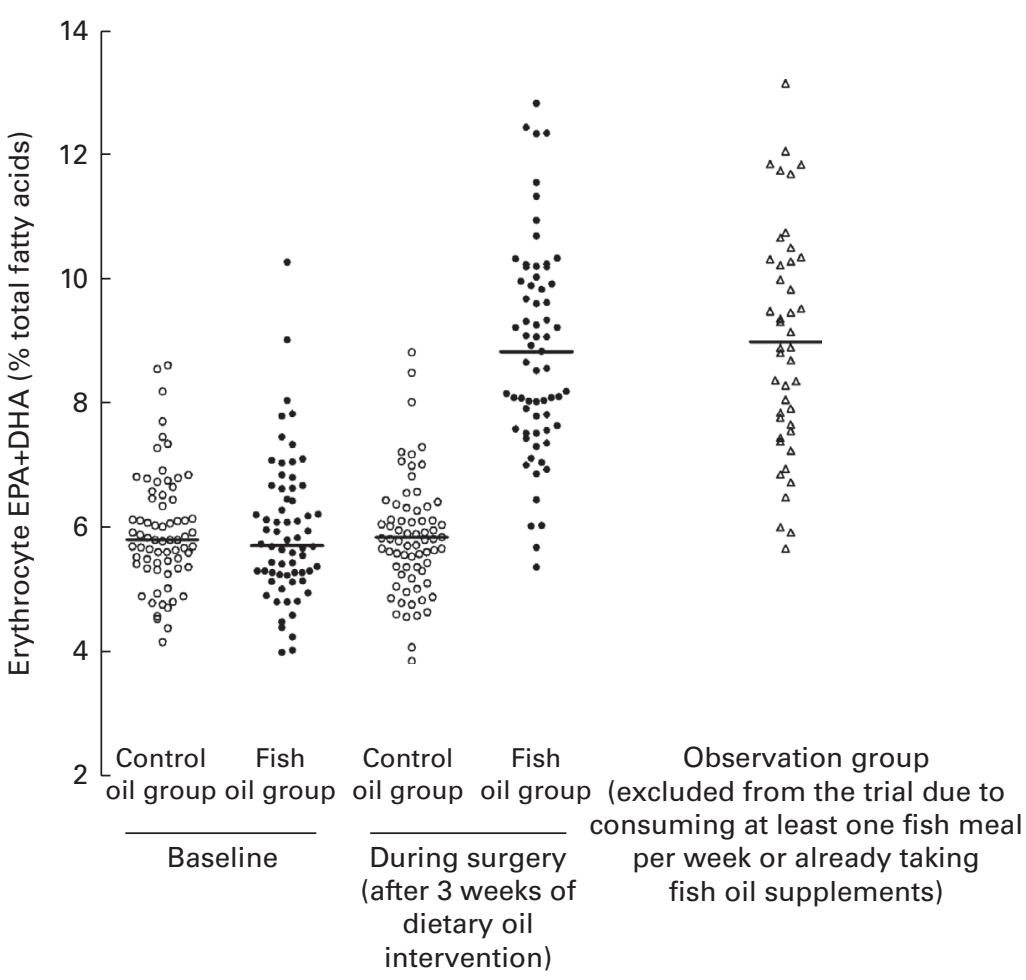

Fig. 2. Erythrocyte EPA+DHA levels in a randomised controlled trial of fish oil intervention for post-operative atrial fibrillation after cardiac surgery. The details of the trial and the mean fatty acid values have been published in Farquharson et al. ${ }^{(45)}$. Control oil group, monounsaturated oil for 3 weeks before surgery $(n 71)$; fish oil group, fish oil concentrate supplying $4.5 \mathrm{~g} / \mathrm{d}$ of EPA+DHA for 3 weeks before surgery $(n 66)$; observation group, excluded from the trial due to the consumption of one or more than one fish meal per week or fish oil supplementation - agreed to be followed $(n 44)$.

between-group difference in mean EPA+DHA levels while also minimising the within-group variability.

There is also relevance for study design. If baseline $n-3$ intakes and/or $n-3$ tissue levels are at or near the extreme of the linear range for influencing cardiac outcomes, the clinical effect of an intervention providing more $n-3$ fats is greatly weakened. Mozaffarian \& Rimm ${ }^{(46)}$ pooled data from twenty cohort studies and randomised trials to generate a spline plot of the relative risk of CHD death against EPA+DHA intake. This plot demonstrated a dose-response from very low intake up to $250 \mathrm{mg} / \mathrm{d}$ of EPA+DHA and then little further reduction with higher intakes ${ }^{(46)}$ (Fig. 3).

Similar relationships were observed in a meta-analysis of eleven prospective cohort studies that examined the doseresponse between the intake of fish and the risk of CHD death $^{(47)}$ and also in a study with a single cohort that specifically examined sudden cardiac death ${ }^{(48)}$. The meta-analysis incorporated studies that commenced from 1958 to 1989 with the average baseline year being 1972. A plot of the weighted relative risks for all categories of fish intake in each of the cohort studies demonstrated a significant protective effect of low fish intake compared with no intake, but then diminishing protection with increased intake ${ }^{(47)}$. Similarly, the study that examined sudden cardiac death showed that dietary fish intake was associated with a reduction in the risk of sudden cardiac death, but there was a plateau after the consumption of more than one fish meal per week ${ }^{(48)}$.
Thus, the relative change in the risk of CHD mortality with $n-3$ consumption will be greatest when the comparator has consumed little or no $n-3$.

Mozaffarian \& Rimm $^{(46)}$ have integrated these and other observations to predict the relationships between $\mathrm{EPA}+\mathrm{DHA}$ intake and various clinical or biomarker cardiovascular outcomes (Fig. 4).

\section{Endpoints}

Besides the issue with background intakes that may be near or above the plateau for effect, the composite endpoint is an

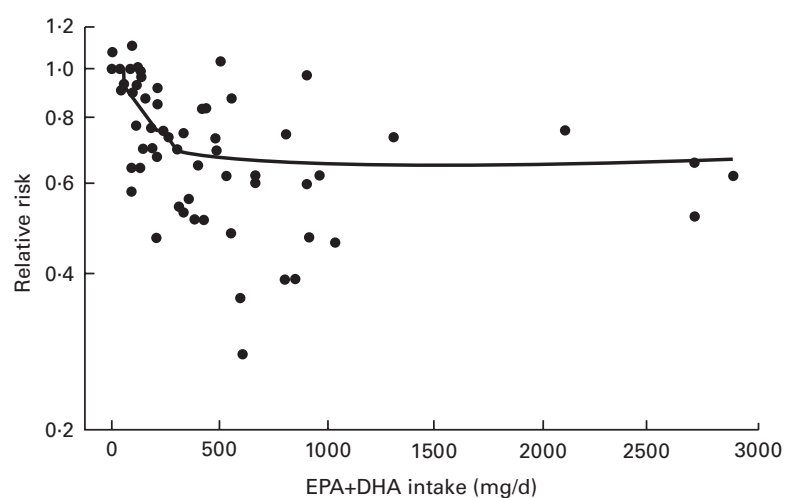

Fig. 3. Relative risk of $\mathrm{CHD}$ death with the intake of the $n-3$ fats, EPA and DHA (adapted from Mozaffarian \& Rimm ${ }^{(46)}$ ). 


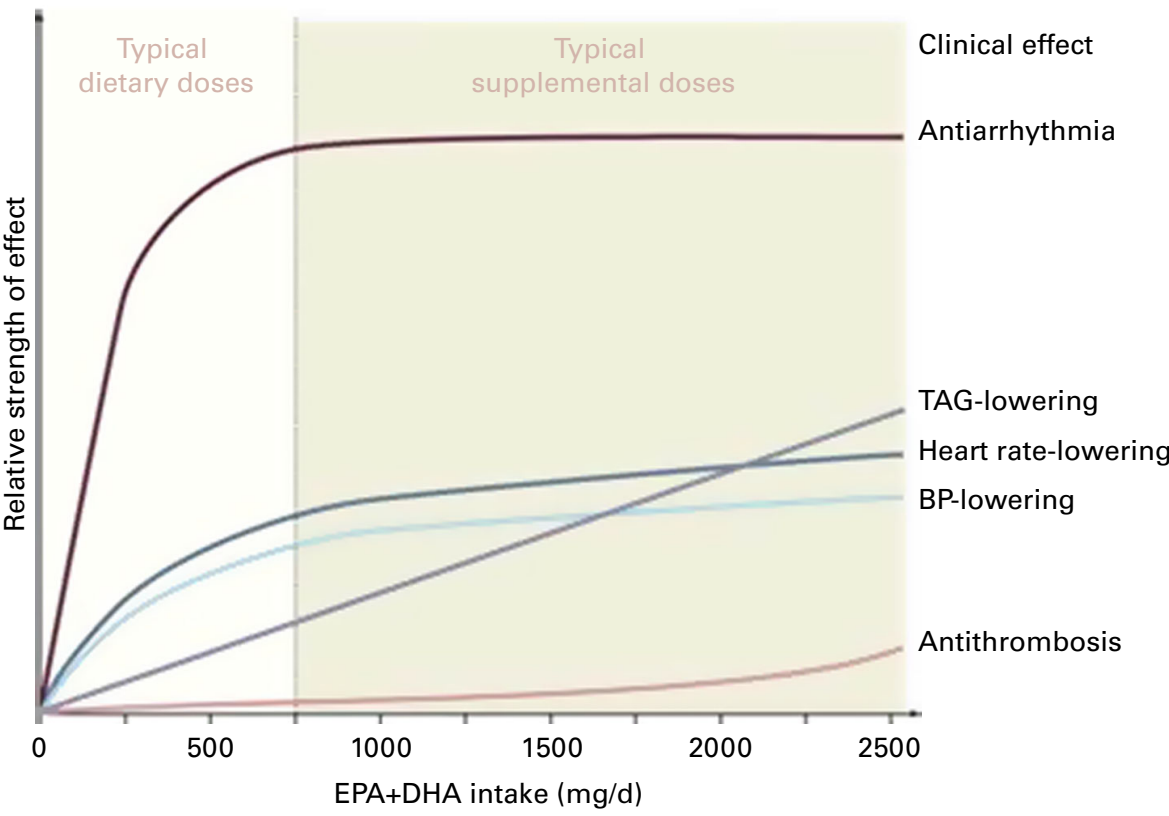

Time course to alter clinical events

Weeks

Months to years

Months

Months to years

Weeks

Fig. 4. Potential dose-responses for clinical events with the intake of the $n-3$ fats, EPA and DHA (adapted from Mozaffarian \& Rimm ${ }^{(46)}$ ). BP, blood pressure. A

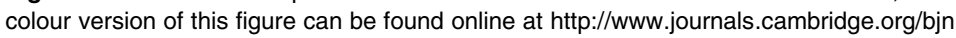

additional problem. The cohort studies, case-control studies and RCT that do find an effect of $n-3$ fat intake on coronary mortality generally find no effect on non-fatal myocardial infarction $^{(3)}$. This can be explained if the main cardiac effect of $n-3$ fats at modest doses is the prevention of fatal arrhythmia. Therefore, inclusion of outcomes for which there is little or no evidence of an effect of $n-3$ fats, such as nonfatal cardiovascular events, percutaneous interventions and coronary artery bypass grafting (CABG), in a composite primary endpoint greatly increases the chance of a null finding even if fish oil intake is associated with one of the components of the composite primary outcome measure, and this point has been made by others ${ }^{(43)}$. During the Alpha Omega Study, it was realised that the event rate of the original primary endpoint of fatal CHD would be too low and therefore major cardiovascular events were considered to be the primary endpoint, which was a composite of fatal and non-fatal myocardial infarction, sudden death, mortality from heart failure, non-fatal stroke and fatal stroke, percutaneous intervention and $\mathrm{CABG}^{(49)}$. This is expected to greatly decrease the chance of detecting an effect on the primary outcome measure, which is always the main aim of a RCT

This is not an issue unique to $n-3$ studies. The problems arising from composite endpoints in drug trials have been outlined, and these centre on the interpretation of results. The trial may show a benefit of a drug on a composite endpoint where the benefit is driven only by a single element of the composite endpoint, but the announcements that accompany the results can imply, by association, that there is a benefit for all elements of the outcome measure ${ }^{(50)}$.

\section{Conclusions}

RCT are accepted methods for examining drugs, and the reasons are obvious. They can show causality and they are not impaired by the use of the drug at baseline or in the control group during the trial. These issues are easily controlled, and they contrast greatly with RCT that examine the effects of fish oil supplementation in cardiac patients. The ability of a RCT to detect changes in CHD mortality will be greatest if the baseline intake of EPA and DHA is very low and non-study EPA+DHA intake is low. If baseline or non-study intake is near or above the threshold for effect, then the RCT is unlikely to show any further effect of an $n-3$ intervention.

It can be argued that none of the issues mentioned above are weaknesses in the conduct of RCT in subjects with cardiac disease because RCT produce answers to the question they are designed to address. For example, the Alpha Omega Study found no effect on a composite outcome that included fatal + non-fatal CVD + percutaneous intervention + CABG of daily consumption of margarine containing $400 \mathrm{mg}$ EPA+DHA in subjects already consuming EPA+DHA at median intakes of 130 (interquartile range $60-210) \mathrm{mg} / \mathrm{d}^{(6)}$. Thus, this amount of dietary EPA+DHA added to a median background intake of $130 \mathrm{mg} / \mathrm{d}$ of EPA+DHA had no effect discernible by this RCT. It was adequately powered and that is the answer. However, an approach that took into account (1) tissue EPA+DHA levels at baseline and where this placed participants on the expected dose-response curve, (2) the effect of study and non-study $n-3$ intake on the final tissue EPA+DHA levels in each group, and (3) the use of existing published information to choose an outcome measure that is more likely to be sensitive to the intervention perhaps could 
have yielded a positive result. Phase III clinical trials with pharmaceuticals invariably consider pharmacokinetics and pharmacodynamics in the planning of the $\operatorname{RCT}^{(51)}$, but $n-3$ trials in CVD patients do not.

This discussion has focused on the shortcomings of individual RCT of fish or fish oil interventions. However, these shortcomings of the test agent being in each group along with the lack of control over baseline $n-3$ status and no allowance for the intervention being in a range where the outcome is responsive to dose inevitably affect the conclusions of meta-analyses.

Analysis of fish oil RCT mirrors that of drug RCT. This is a bygroup comparison of the intention-to-treat sample and it is the standard for publication. This is understandable for drug trials, but the lack of distinct groups in fish oil trials limits the conclusions on efficacy that can be drawn from such an analysis. Given this limitation, it is appropriate to acknowledge the value of post hoc regression analyses that examine the relationships between tissue levels of $n-3$ fats and outcomes. These could accompany the initial publication of the by-group comparisons and assist in drawing the conclusions. It follows that metaregression analyses may be more informative than standard meta-analyses that compared group outcomes.

These limitations point out the relative usefulness of cohort and case-control studies and 'real-life' clinic studies for assessing $n$ - 3 benefits at the community level and the patient level, respectively. An example from the latter category is the retrospective matched cohort analysis of data from the General Practice Research Database in the UK that showed that prescription of licensed $n-3$ fats at a daily dose of $1 \mathrm{~g}$ to patients within $90 \mathrm{~d}$ of a first myocardial infarction reduced all-cause mortality ${ }^{(52)}$. The intention of such a study is the same as that of Phase IV drug trials; that is, to examine how the drug or, in this case, fish oil performs in real-life practice with the vagaries of compliance.

\section{Recommendations for randomised controlled trials with fish oil}

The trial design should aim to maximise the appropriate differences in $n$ - 3 tissue levels between the control and the intervention group(s). The following exclusion criteria should be used:

(1) Exclude those who habitually consume more than one fish meal per week.

(2) Exclude those taking fish oil supplements and are unwilling to discontinue their use.

(3) Exclude those who are not certain that they will not use fish oil or similar $n-3$ supplements for the duration of the trial.

(4) Exclude those whose tissue $n$ - 3 levels are above a certain threshold (realistically this would be erythrocyte $n-3$ levels).

These exclusions will greatly reduce the recruitment of cardiac patients due to the recommendations that they generally receive to increase $n$ - 3 intake.
To address the variability in the relationship between the intake and tissue levels of $n$ - 3 fatty acids, a treat-totarget approach could be used. This would employ dosage adjustment to reach a certain target erythrocyte EPA+DHA level in the intervention group, rather than relying on a fixed dose of fish oil. This would be similar to the approaches followed in statin trials with target LDL levels or diabetes trials with target glycated $\mathrm{Hb}$ levels and anti-hypertensive trials with target blood pressures.

The primary endpoint should not include outcomes for which there is little or no evidence for an effect of dietary $n-3$ fats. This would exclude non-fatal myocardial infarction, hospital admission for cardiovascular causes, percutaneous intervention, and coronary artery bypass surgery, all of which have been used in composite primary endpoints in fish oil trials with cardiac patients ${ }^{(6,8)}$.

Clearly, these criteria would increase the difficulty of conducting RCT involving fish oil supplementation in at-risk cardiac patients. However, to continue further RCT without addressing especially the issue of non-discrete $n-3$ groups and whether baseline $n-3$ intake already places individuals high on the dose-response curve is an inefficient and flawed approach for studying the potential benefits of dietary $n-3$ fats for cardiac mortality.

\section{Acknowledgements}

The review was conceived by M. J. J. and writing contributions were made by M. J. J., T. R. S., R. G. M. and L. G. C.

\section{References}

1. Burr ML, Fehily AM, Gilbert JF, et al. (1989) Effects of changes in fat, fish, and fibre intakes on death and myocardial reinfarction: Diet and Reinfarction Trial (DART). Lancet 334, 757-761.

2. GISSI Prevenzione Investigators (1999) Dietary supplementation with $n-3$ polyunsaturated fatty acids and vitamin $\mathrm{E}$ after myocardial infarction: results of the GISSI-Prevenzione trial. Lancet 354, 447-455.

3. Mozaffarian D \& Wu JH (2011) Omega-3 fatty acids and cardiovascular disease: effects on risk factors, molecular pathways, and clinical events. J Am Coll Cardiol 58, 2047-2067.

4. Harris WS, Kris-Etherton PM \& Harris KA (2008) Intakes of long-chain omega-3 fatty acid associated with reduced risk for death from coronary heart disease in healthy adults. Curr Atheroscler Rep 10, 503-509.

5. Bosch J, Gerstein HC, Dagenais GR, et al. (2012) n-3 Fatty acids and cardiovascular outcomes in patients with dysglycemia. N Engl J Med 367, 309-318.

6. Kromhout D, Giltay EJ \& Geleijnse JM (2010) n-3 Fatty acids and cardiovascular events after myocardial infarction. $N$ Engl J Med 363, 2015-2026.

7. Rauch B, Schiele R, Schneider S, et al. (2010) OMEGA, a randomized, placebo-controlled trial to test the effect of highly purified omega-3 fatty acids on top of modern guidelineadjusted therapy after myocardial infarction. Circulation 122, 2152-2159. 
8. The Risk and Prevention Study Collaborative Group (2013) $n$-3 Fatty acids in patients with multiple cardiovascular risk factors. $N$ Engl J Med 368, 1800-1808.

9. Meldrum ML (2000) A brief history of the randomized controlled trial. From oranges and lemons to the gold standard. Hematol Oncol Clin North Am 14, 745-760.

10. Munos B (2009) Lessons from 60 years of pharmaceutical innovation. Nat Rev Drug Discov 8, 959-968.

11. Steg PG, Lopez-Sendon J, Lopez de Sa E, et al. (2007) External validity of clinical trials in acute myocardial infarction. Arch Intern Med 167, 68-73.

12. Rothwell PM (2006) Factors that can affect the external validity of randomised controlled trials. PLOS Clin Trials 1, e9.

13. Pincus T \& Sokka T (2004) Should contemporary rheumatoid arthritis clinical trials be more like standard patient care and vice versa? Ann Rheum Dis 63, Suppl. 2, ii32-ii39.

14. Kaul S \& Diamond GA (2010) Trial and error. How to avoid commonly encountered limitations of published clinical trials. J Am Coll Cardiol 55, 415-427.

15. Bero L, Oostvogel F, Bacchetti $\mathrm{P}$, et al. (2007) Factors associated with findings of published trials of drug-drug comparisons: why some statins appear more efficacious than others. PLOS Med 4, e184.

16. Burr ML, Ashfield-Watt PA, Dunstan FD, et al. (2003) Lack of benefit of dietary advice to men with angina: results of a controlled trial. Eur J Clin Nutr 57, 193-200.

17. Rizos EC, Ntzani EE, Bika E, et al. (2012) Association between omega-3 fatty acid supplementation and risk of major cardiovascular disease events: a systematic review and meta-analysis. JAMA 308, 1024-1033.

18. Garbagnati F, Cairella G, De Martino A, et al. (2009) Is antioxidant and $n-3$ supplementation able to improve functional status in poststroke patients? Results from the Nutristroke Trial. Cerebrovasc Dis 27, 375-383.

19. Sacks FM, Stone PH, Gibson CM, et al. (1995) Controlled trial of fish oil for regression of human coronary atherosclerosis. HARP Research Group. J Am Coll Cardiol 25, 1492-1498.

20. Leng GC, Lee AJ, Fowkes FG, et al. (1998) Randomized controlled trial of $\gamma$-linolenic acid and eicosapentaenoic acid in peripheral arterial disease. Clin Nutr 17, 265-271.

21. Ness AR, Ashfield-Watt PA, Whiting JM, et al. (2004) The long-term effect of dietary advice on the diet of men with angina: the diet and angina randomized trial. J Hum Nutr Diet 17, 117-119.

22. Page IH, Allen EV, Chamberlain FL, et al. (1961) Dietary fat and its relation to heart attacks and strokes. Circulation 23, 133-136.

23. Kim HJ, Giovannucci E, Rosner B, et al. (2014) Longitudinal and secular trends in dietary supplement use: Nurses' Health Study and Health Professionals Follow-up Study, 1986-2006. J Acad Nutr Diet 114, 436-443.

24. Krauss RM, Eckel RH, Howard B, et al. (2000) AHA Dietary Guidelines: revision 2000: a statement for healthcare professionals from the Nutrition Committee of the American Heart Association. Circulation 102, 2284-2299.

25. Kris-Etherton PM, Harris WS \& Appel LJ (2002) Fish consumption, fish oil, omega- 3 fatty acids, and cardiovascular disease. Circulation 106, 2747-2757.

26. Shepherd CJ \& Jackson AJ (2013) Global fishmeal and fish oil supply: inputs, outputs, and markets. J Fish Biol 83, 1046-1066.

27. Bimbo AP (2013) The evolution of fish oils to omega 3 fatty acids and a global consumer market of US\$25 billion+. Paper presented at the West Virginia University Research Corporation Forum Linking Innovation, Industry, and Commercialization (LIINC), Dean's Open Forum on Innovation and Entrepreneurship, Davis College of Agriculture, Natural
Resources \& Design, Morgantown, WV, USA, April 25, 2013. http://www.innovation.research.wvu.edu/r/download/ 158952 (accessed June 2014).

28. Howe P, Meyer B, Record S, et al. (2006) Dietary intake of long-chain omega-3 polyunsaturated fatty acids: contribution of meat sources. Nutrition 22, 47-53.

29. Brenna JT, Salem N Jr, Sinclair AJ, et al. (2009) $\alpha$-Linolenic acid supplementation and conversion to $n$-3 long-chain polyunsaturated fatty acids in humans. Prostaglandins Leukot Essent Fatty Acids 80, 85-91.

30. Burdge GC \& Calder PC (2005) Conversion of $\alpha$-linolenic acid to longer-chain polyunsaturated fatty acids in human adults. Reprod Nutr Dev 45, 581-597.

31. Rosell MS, Lloyd-Wright Z, Appleby PN, et al. (2005) Longchain $n-3$ polyunsaturated fatty acids in plasma in British meat-eating, vegetarian, and vegan men. Am J Clin Nutr 82, 327-334.

32. Welch AA, Shakya-Shrestha S, Lentjes MA, et al. (2010) Dietary intake and status of $n-3$ polyunsaturated fatty acids in a population of fish-eating and non-fish-eating meat-eaters, vegetarians, and vegans and the product-precursor ratio [corrected] of $\alpha$-linolenic acid to long-chain $n$-3 polyunsaturated fatty acids: results from the EPIC-Norfolk cohort. $A m \mathrm{~J}$ Clin Nutr 92, 1040-1051.

33. Metcalf RG, Cleland LG, Gibson RA, et al. (2010) Relation between blood and atrial fatty acids in patients undergoing cardiac bypass surgery. Am J Clin Nutr 91, 528-534.

34. Siscovick DS, Raghunathan TE, King I, et al. (1995) Dietary intake and cell membrane levels of long-chain $n$-3 polyunsaturated fatty acids and the risk of primary cardiac arrest. JAMA 274, 1363-1367.

35. Albert CM, Campos H, Stampfer MJ, et al. (2002) Blood levels of long-chain $n$-3 fatty acids and the risk of sudden death. $N$ Engl J Med 346, 1113-1118.

36. Harris WS \& Von Schacky C (2004) The Omega-3 Index: a new risk factor for death from coronary heart disease? Prev Med 39, 212-220.

37. Mozaffarian D, Lemaitre RN, King IB, et al. (2013) Plasma phospholipid long-chain $\omega-3$ fatty acids and total and cause-specific mortality in older adults: a cohort study. Ann Intern Med 158, 515-525.

38. Harris WS, Pottala JV, Lacey SM, et al. (2012) Clinical correlates and heritability of erythrocyte eicosapentaenoic and docosahexaenoic acid content in the Framingham Heart Study. Atherosclerosis 225, 425-431.

39. James MJ, Proudman SM \& Cleland LG (2010) Fish oil and rheumatoid arthritis: past, present and future. Proc Nutr Soc 69, 316-323.

40. Flock MR, Skulas-Ray AC, Harris WS, et al. (2013) Determinants of erythrocyte omega-3 fatty acid content in response to fish oil supplementation: a dose-response randomized controlled trial. J Am Heart Assoc 2, e000513.

41. Krul ES, Lemke SL, Mukherjea R, et al. (2012) Effects of duration of treatment and dosage of eicosapentaenoic acid and stearidonic acid on red blood cell eicosapentaenoic acid content. Prostaglandins Leukot Essent Fatty Acids 86, 51-59.

42. von Schacky C (2014) Omega-3 index and cardiovascular health. Nutrients 6, 799-814.

43. Wu JH \& Mozaffarian D (2014) $\omega$-3 Fatty acids, atherosclerosis progression and cardiovascular outcomes in recent trials: new pieces in a complex puzzle. Heart 100, 530-533.

44. Harris WS (2013) Are $n$-3 fatty acids still cardioprotective? Curr Opin Clin Nutr Metab Care 16, 141-149.

45. Farquharson AL, Metcalf RG, Sanders P, et al. (2011) Effect of dietary fish oil on atrial fibrillation after cardiac surgery. $A m J$ Cardiol 108, 851-856. 
46. Mozaffarian D \& Rimm EB (2006) Fish intake, contaminants, and human health: evaluating the risks and the benefits JAMA 296, 1885-1889.

47. He K, Song Y, Daviglus ML, et al. (2004) Accumulated evidence on fish consumption and coronary heart disease mortality: a meta-analysis of cohort studies. Circulation 109, 2705-2711.

48. Albert CM, Hennekens CH, O'Donnell CJ, et al. (1998) Fish consumption and risk of sudden cardiac death. JAMA $\mathbf{2 7 9}$ 23-28.

49. Geleijnse JM, Giltay EJ, Schouten EG, et al. (2010) Effect of low doses of $n$-3 fatty acids on cardiovascular diseases in 4,837 post-myocardial infarction patients: design and baseline characteristics of the Alpha Omega Trial. Am Heart J 159, 539-546.e532.
50. Loscalzo J (2005) Clinical trials in cardiovascular medicine in an era of marginal benefit, bias, and hyperbole. Circulation 112, 3026-3029.

51. Chien JY, Friedrich S, Heathman MA, et al. (2005) Pharmacokinetics/pharmacodynamics and the stages of drug development: role of modeling and simulation. AAPS I 7, E544-E559.

52. Poole CD, Halcox JP, Jenkins-Jones S, et al. (2013) Omega-3 fatty acids and mortality outcome in patients with and without type 2 diabetes after myocardial infarction: a retrospective, matched-cohort study. Clin Ther 35, 40-51.

53. Rauch B, Schiele R, Schneider S, et al. (2006) Highly purified omega-3 fatty acids for secondary prevention of sudden cardiac death after myocardial infarction-aims and methods of the OMEGA-study. Cardiovasc Drugs Ther 20, 365-375. 